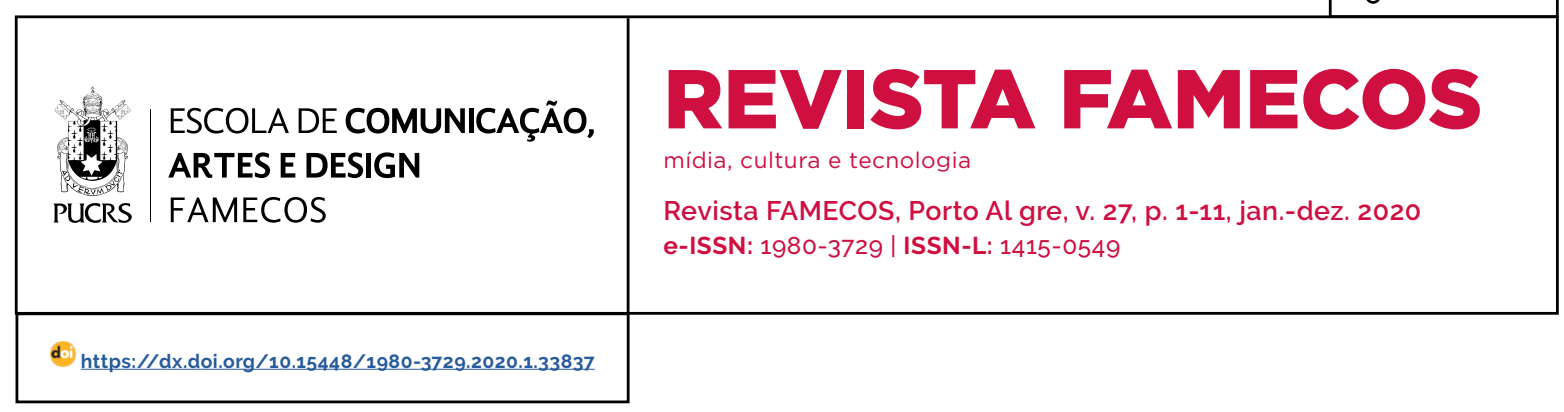

AUDIOVISUAL

\title{
Tramas do tempo no telejornalismo local: temporalidades sociais no programa Terra de Minas
}

\author{
The framing of time in the local telejournalism: social temporalities in \\ the program Terra de Minas
}

Tramas del tiempo en el teleperiodismo local: temporalidades sociales en el programa Terra de Minas

\section{Fernanda Mauricio da Silva ${ }^{1}$} orcid.org/0000-0003-3661-6475 fernandamauricio@gmail.com

Recebido em: 2 abr. 2019. Aprovado em: 21 ago. 2019. Publicado em: 16 jul. 2020.

\section{(c) (1)}

Artigo está licenciado sob forma de uma licença Creative Commons Atribuição 4.0 Internacional.
RESUMO: O presente artigo tem como objetivo analisar a forma como o programa Terra de Minas (TV Globo Minas) aborda diferentes temporalidades como forma de estabelecer uma imagem da cidade de Belo Horizonte. A partir das contribuições dos Estudos Culturais, este artigo assume o passado como algo não finalizado, mas é convocado no presente podendo assumir lugares de disputa e oposição às formas dominantes. Do mesmo modo, o futuro pode ser vivido no presente, não como algo projetado, mas como aquilo que reconfigura elementos do dominante ou que instaura algo novo. A análise textual do programa, embasada em seus elementos visuais, sonoros e verbais, sinaliza para pelo menos três convocações das temporalidades sociais: o passado como patrimônio, o futuro como aprimoramento do passado e o passado como construção dos sujeitos. Palavras-chave: Telejornalismo local. Temporalidades sociais. Terra de Minas.

ABSTRACT: This article analyzes how the program called Terra de Minas (TV Globo Minas) addresses different temporalities as a way to establish an image of the city of Belo Horizonte. Based on the contributions of Cultural Studies, this article assumes that the past is not something that is finalized, but it is summoned in the present and may assume places of dispute and opposition to the dominant forms. In the same way, the future can be lived in the present, not as something projected, but as that which reconfigures elements of the dominant or that establishes something new. The textual analysis of the program, based on its visual, sound and verbal elements, signals for at least three calls of social temporalities: the past as patrimony, the future as an improvement of the past and the past as a construction of oneself.

Keywords: Local telejournalism. Social temporality. Terra de Minas.

RESUMEN: El presente artículo tiene como objetivo analizar la forma en que el programa Tierra de Minas (TV Globo Minas) aborda diferentes temporalidades como forma de establecer una imagen de la ciudad de Belo Horizonte. A partir de las contribuciones de los Estudios Culturales, este artículo asume que el pasado no es algo finalizado, pero es convocado en el presente pudiendo asumir lugares de disputa y oposición a las formas dominantes. De la misma manera, el futuro puede ser vivido en el presente, no como algo proyectado, sino como aquello que reconfigura elementos del dominante o que instaura algo nuevo. El análisis textual del programa, basado en sus elementos visuales, sonoros y verbales, señala para al menos tres convocatorias de las temporalidades sociales: el pasado como patrimonio, el futuro como perfeccionamiento del pasado y el pasado como construcción de los sujetos.

Palabras clave: Teleperiodismo local. Temporalidades sociales. Terra de Minas. 


\section{Introdução}

Terra de Minas é um programa de grandes reportagens que estreou em 2001 na TV Globo Minas. Com edições semanais, o jornalístico tem como parte de sua pauta mostrar diferentes localidades do estado e diferentes modos de viver, especialmente em cidades do interior. A capital mineira, Belo Horizonte (BH), se constrói no programa como símbolo da modernidade, o que se ratifica nas imagens da igreja de São Francisco, do Edifício Niemeyer e na paisagem urbana. Assim, BH representa um lugar de contradição para a afirmação do discurso hegemônico sobre estado defendido no Terra de Minas: ao mesmo tempo que traz "o progresso" e insere o estado em um cenário de modernidade, essa mesma modernidade impede a manutenção dos valores tradicionais que definem, segundo a emissora, o mineiro: simpatia, tranquilidade, simplicidade ${ }^{2}$.

Muito do programa Terra de Minas consiste em dar visibilidade aos locais onde se pode encontrar tais valores tradicionais. As práticas e diferentes modos de viver dizem de outra temporalidade, de um passado que o programa procura resgatar enquanto resíduo, enquanto aspecto ainda ativo na sociedade. Mas o que dizer da cidade de Belo Horizonte retratada no programa? De que forma tradição e modernidade dialogam no mesmo espaço televisivo? Que tensionamentos são encontrados entre passado, presente e futuro? O objetivo deste artigo é fomentar uma discussão sobre as distintas temporalidades acionadas pelo programa Terra de Minas para retratar a cidade de Belo Horizonte. O programa projeta ao telespectador uma experiência temporal, uma forma de estar no mundo que articula dimensões identitárias a uma relação especifica com o espaço-tempo. De que forma ele o faz, como passado, presente e futuro aparecem articulados nas formas do programa, e ainda, tomando Belo Horizonte como cenário e problema, de que forma as temporalidades disputam a construção de uma imagem que põe em contradição a ideia de "cidade do futuro" e a necessidade de preservação do passado são algumas das questões de fundo deste artigo.

A análise do programa apresenta oito reportagens exibidas entre os anos de 2015 e 2017, que demonstram os deslocamentos das temporalidades acionados enquanto forma midiática. Antes, porém, faremos uma breve contextualização do programa Terra de Minas no cenário do telejornalismo local, buscando compreender suas matrizes culturais e sua inserção no gênero televisivo. Em seguida, trataremos a questão da temporalidade nos estudos comunicacionais trazendo as contribuições, principalmente, dos Estudos Culturais. Deste modo, este artigo assume, como lugar teóricometodológico, um olhar para o tempo enquanto categoria que se mantém dinâmica na vida social e é acionada pelos produtos midiáticos em uma relação próxima à vida cotidiana.

\section{O Terra de Minas e o telejornalismo local}

Terra de Minas é um programa produzido e exibido pela TV Globo Minas, uma versão regional da Rede Globo de Televisão. Indo ao ar nas tardes de sábado desde outubro de 2001, o programa possui a seguinte descrição:

Juliana Perdigão lapresentadora] leva
ao público as histórias, as tradições e
os personagens fascinantes de Minas
Gerais aos sábados. Ela apresenta o
Terra de Minas, programa que viaja
pelo estado para mostrar o patrimônio
histórico e cultural mineiro3 (TERRA DE
MINAS, [2017], grifo nosso).

Apesar do forte sentido de pertencimento construido pelo programa, ele também é transmitido para mais de 130 países pela Globo Internacional. Assim, a emissora aposta no local como elemento de exportação, como marca das características do estado que, por vezes, se confundem com marcas do próprio Brasil. Por conta

\footnotetext{
2 Nos anos de 2009 e 2010, a TV Globo Minas fez uma campanha publicitária que tinha como eixo elementos que a emissora considera relevantes na formação identitária do estado. Os spots iam ao ar ao longo da programação e consistiam em uma trilha musical de artistas locais acompanhados por imagens de paisagens do estado.

3 TERRA DE MINAS. O programa. Minas, Rede Globo, 31 jan. 2017. Disponivel em: https://redeglobo.globo.com/globominas/terrademinas/noticia/o-programa.ghtml. Acesso em: 18 out. 2017
} 
disso, o Terra de Minas possui um forte tom turistico, como se se endereçasse ao turista de passagem.

Terra de Minas é um programa de grandes reportagens que assume um modelo próximo aos programas de turismo vistos principalmente na TV fechada, mas guarda as convenções dominantes do telejornalismo presentes em qualquer manual de redação. O programa perscruta vilarejos, valoriza monumentos, mostra curiosidades, ensina receitas ancestrais, tudo isso sob o enfoque de uma tradição que constitui a identidade local.

A pesquisa em comunicação possui uma ampla literatura a respeito das relações entre televisão local e formação/representação da identidade. Em muitas dessas abordagens, o objeto de análise são os telejornais diários exibidos pelas emissoras regionais dispersas pelo País (MATA, 2011; COUTINHO; MATA, 2010; LISBOA FILHO; ENNINGER, 2013). Lisboa Filho e Enninger (2013) explicam que a delimitação de um território, a partilha de certos valores e práticas e a disseminação de um mito fundador são recursos empregados para a construção de um sentido de unicidade. Coutinho e Mata (2010) defendem que a programação televisiva atua na formação de um laço de pertencimento que oculta os dissensos e procura estabelecer um consenso a respeito do que significa "pertencer".

Em um estudo sobre a construção identidade juiz-forana em telejornais da TV Alterosa, TVE e Globo Minas, Mata afirma que

A TV local, por seu pioneirismo e papel de integração, não deixou de unir os laços sociais da modernidade, inspirando-se nas suas tradições regionais para elaborar seus programas, mesmo com toda influência das grandes redes (MATA, 2011, p. 42)

Não é a apenas a televisão local que gera sentidos de pertencimento por uma vinculação mais evidente com elementos reconheciveis pelos públicos que deles partilham - os bairros, os eventos, as celebrações etc. - mas é papel do próprio jornalismo conferir uma experiência que engloba produção e recepção. Os laços de pertencimento de que nos falam Coutinho e Mata (2010) são ratificados por um sentido de "estar no mundo" compartilhado no momento da transmissão do programa. Por esta razão, tem sido cada vez mais comum, nos programas jornalísticos, os telespectadores enviarem fotos e vídeos em sua residência, em espaços públicos das cidades, em momentos de lazer, ou seja, pessoas comuns em sua vida cotidiana exibem-se na programação local em uma relação contínua entre o tempo midiático e o tempo da experiência do dia a dia4.

Buscando caracterizar a experiência estética a partir do prazer gerado pela socialização dos individuos, Mead (1926) chama atenção para o fato de que as experiências, quando vividas em conjunto, são apreendidas a partir de uma dimensão de deleite, que envolve o simples fato de colocar as pessoas em contato em direção a uma finalidade comum. Para Mead, a experiência parte da necessidade de interpretar as complexidades da vida social em termos dos objetivos e dos esforços dos individuos em alcançá-los.

Com base nisso, o autor reconhece no cinema e no jornalismo formas de obter prazer por meio da recepção coletiva do produto. A simples leitura dos jornais (diariamente, pela manhã, por exemplo) e o contato com assuntos comuns provocam uma recepção prazerosa, uma vez que ultrapassa o nível do pessoal e une os individuos em torno de questões vividas socialmente. Sendo assim, o caráter generalizante dos assuntos pautados pelo jornalismo permite uma experiência comunitária e a identificação do grupo social ao qual o indivíduo faz parte.

O telejornalismo local, por buscar maior proximidade com sua audiência (COUTINHO; MATA, 2010), constitui-se como um espaço profícuo para dar sentido às experiências comuns e transmiti-las a outros. São esses significados que, segundo Mead (1926), permitem a percepção do "mundo real" e a socialização dos indivíduos a partir de um sentimento de apreciação e prazer

4 O Terra de Minas, por exemplo, utiliza imagens de pessoas comuns nos cenários explorados pelo programa: cidades históricas, cachoeiras etc. Tudo isso reforça o papel do telejornalismo em possibilitar a partilha do mesmo tempo-espaço (aqui-agora) em uma experiência contínua. 
pelo simples fato de ser compartilhado com outros. Assim, se o telejornalismo local permite uma experiência no e do espaço em busca da construção de laços sociais, faz-se relevante entender também como a categoria do tempo pode ratificar esses valores.

\section{Temporalidades sociais, temporalidades midiáticas}

A questão das temporalidades encontra-se em crescimento nas pesquisas em comunicação, não tanto no sentido de meramente atribuir-lhe um caráter histórico, mas pelo reconhecimento de que a cultura contemporânea é atravessada por tempos distintos. Se a linearidade histórica já ocupou o ponto de partida para a consideração dos fenômenos comunicacionais, na atualidade percebe-se que os tempos possuem movimentos dinâmicos, implicando diversos ires-e-vires em sentidos múltiplos. A experiência com o tempo, portanto, está se modificando. Elementos do passado emergem no presente e reconfiguram-se em novas práticas. Para Musse, Vargas e Nicolau,

[...] cada mídia e cada processo comunicacional engendra um ou mais regimes de temporalidade. Cada um deles traduz o tempo e sua percepção de maneira peculiar conforme o uso social e simbólico que a sociedade faz dessa mediatização (MUSSE; VARGAS; NICOLAU, 2017, p. 8).

Essa trama requer, primeiramente, considerar o presente como algo não cristalizado em processos solidificados, mas de forma fluida e em permanente transformação. Concordamos com Ribeiro, Leal e Gomes quando afirmam que

O presente é vivo, portanto, porque é histórico, porque permite a reconfiguração constante do passado e do futuro. Todo narrar, todo esforço de configurar a experiência temporal - midiático inclusive - resulta, então, desse agir, se constitui como uma operação de produção de sentido, de configuração de mundos, a partir da proposição de uma experiência do tempo, ao configurar presente, passado e futuro. (RIBEIRO; LEAL; GOMES, 2017, p. 39).
É por partilhar essa forma de entender as temporalidades que efetuamos um percurso de aproximação aos Estudos Culturais, corrente de investigação que teve, desde sua origem, uma preocupação central com o tempo e suas tramas (SILVA; GUTMANN, 2017). Embasados em MartínBarbero, Ribeiro, Leal e Gomes destacam que a "multiplicidade de temporalidades, multiplicidade de histórias, com seus próprios ritmos e com suas próprias lógicas" (MARTIN-BARBERO, 2006, p. 43) atravessam os processos culturais e midiáticos, estabelecendo uma nova perspectiva de observação dos fenômenos. Ainda de acordo com Ribeiro, Leal e Gomes (2017, p. 53), Martín-Barbero encontra apoio nas formulações de Raymond Williams para afirmar que cada sociedade vive uma heterogeneidade de temporalidades, ou seja, em um mesmo momento histórico vivese aspectos arcaicos, residuais e emergentes. Assim, retomaremos as formulações de Williams para entendermos de que forma as distintas temporalidades convivem simultaneamente na sociedade e configuram o processo cultural.

Williams (1979) considera que a cultura é marcada por um jogo de disputas entre valores distintos assumidos como dominantes em um certo periodo histórico. Assim, formas hegemônicas a todo momento concorrem com formas alternativas e oposicionais (WILLIAMS, 2011b) para se estabelecer como dominante. Essas disputas podem provocar transformações (leves ou severas) nos modos de viver de uma sociedade em um dado momento histórico, assim, como transforma sua arte, sua literatura, sua linguagem, suas práticas cotidianas. Para Williams, a cultura é um processo sempre dinâmico e em transformação, que se evidencia em convenções dominantes, mas que não descarta formas já vividas no passado. Para dar conta dessas diferentes categorias de tempo, o autor formulou as noções de arcaico, residual e emergente, que trataremos a seguir.

O residual diz respeito aos aspectos vividos no passado que permanecem ativos no processo cultural por meio de uma reconfiguração no presente, podendo apresentar-se como alternativo 
ou opositor. A relação entre o dominante e o residual convoca uma tradição seletiva, ou seja, "a forma pela qual, a partir de toda uma área possivel do passado e do presente, certos significados e práticas são escolhidos e enfatizados, enquanto outros significados e práticas são negligenciados e excluidos" (WILLIAMS, 2011b, p. 54). A noção de residual segundo o autor não pode confundir-se com a de arcaico, ou seja, das formas que tiveram uma existência no passado, mas deixaram de existir completamente.

Já o emergente refere-se àquilo que está presente na sociedade de forma ainda virtual. São os "novos valores, novas práticas, novas relações e tipos de relação [que] estão sendo continuamente criados" (WILLIAMS, 1979, p. 126) e que resistem à cultura dominante. O conceito de emergente não pode se confundir com o de "inovação" que, segundo o autor, representa a reprodução da ordem dominante a fim de ratificá-la e dar-lhe força. A inovação acontece dentro da cultura dominante, enquanto o emergente teria o papel de negá-la, atuando como uma forma cultural de oposição. Deste modo, para Williams (1979), em um mesmo momento estão incorporadas diversas temporalidades, que, postas em relação, possibilitam olhar as articulações entre presente, passado e futuro ${ }^{5}$.

É a partir dessas noções que Gomes afirma que

o analista precisa considerar as diversas temporalidades sociais em qualquer análise da cultura e estar atento a um certo senso de movimento, de processo histórico, de conexões com o futuro e o passado, de articulações complexas entre esses elementos dominantes e os residuais e emergentes (GOMES, 2011, p. 44).

Tendo em vista as noções de residual, emergente e dominante, mas também de arcaico e de tradição seletiva, procedemos à análise do programa Terra de Minas em um esforço inicial de desvendar, ao menos em parte, essas complexas articulações das múltiplas temporalidades que atravessam o programa. Nesta análise, procuramos demonstrar de que forma passado, presente e futuro estão concatenados provocando distintas formas de ver o tempo.

\section{Continuidades e rupturas temporais no Terra de Minas}

Propõe-se, então, uma análise do programa Terra de Minas com base em seus elementos sonoros, visuais e verbais. Para tanto, selecionamos, aleatoriamente, seis edições do programa que tiveram ao menos uma reportagem centrada em elementos da capital: uma em 2015 (7 mar. 2015), três em 2016 (7 maio 2016a; 14 maio 2016b; 25 jun. 2016c) e duas em 2017 (18 nov. 2017a; 9 dez. 2017a). Foi com base nelas que localizamos distintas formas de aparição e tratamento das temporalidades que revelam uma presença tensionada entre elas. Discutiremos a seguir as principais delas.

\section{O passado como patrimônio}

O Terra de Minas usa referências ao passado para legitimar os modos de vida do estado através das histórias que certos personagens têm para contar e que revelam algo do passado. o programa refere-se ao passado como um tempo onde se viviam as autênticas (e puras) relações sociais, ao contrário do presente, que é definido pela correria. Terra de Minas alonga o passado e busca preservá-lo como um patrimônio no presente. A dicotomia "passado tranquilo" $x$ "presente acelerado" é o modo mais evidente de posicionamento das distintas temporalidades sociais vividas em um mesmo momento histórico. Isto se mostra tanto nas falas dos agentes do programa, quanto dos sujeitos entrevistados. $\mathrm{Na}$ abertura da reportagem que inicia o programa no dia 7 de março 2015, enquanto a apresentadora Juliana Perdigão encontra-se em um café no centro da cidade de Belo Horizonte, a repórter Viviane Possato está ao lado de fora, na rua, reforçando o sentido de correria:

\footnotetext{
5 Segundo Gomes (2011), as noções de dominante, residual e emergente estão presentes na hipótese cultural da "estrutura de sentimento", termo que designa os aspectos vividos que se encontram em processo, sempre em uma posição cambiante. Para uma consideração mais detalhada e uma análise de um produto comunicacional a partir da noção de estrutura de sentimento, ver Silva e Gutmann (2017).
} 
Juliana Perdigão: Para começar a gente vai falar da arte de fazer café, ou melhor, de uma artista que decidiu fazer arte com o café. Ela mostra que às vezes interromper a pressa com um cafezinho coado na hora faz um bem danado pra gente.

Viviane Possato: ela faz isso aqui no centro da cidade mesmo. Imagine você andando apressado no meio desta multidão. De repente surge o convite: tomar um cafezinho logo cedo (TERRA DE MINAS, 2015).

A atuação das jornalistas enfatiza os sentidos pretendidos pela reportagem: Viviane Possato instaura um aqui (rua) - agora (horário de movimento) reconhecido pelo telespectador residente em grandes centros urbanos. A partilha da experiência do tempo apressado do presente torna-se uma maneira do programa vincular-se à audiência, por isso, estratégia semelhante se repete em diversas edições do programa: a repórter lana Coimbra coloca-se em um movimentado cruzamento de veículos no centro da cidade e pergunta: "qual a imagem que você tem do centro de Belo Horizonte? Trânsito? Barulho? Ruas cheias?" (7 maio 2016a); o repórter Vladmir Vilhaça usa a expressão "ritmo frenético" para definir as ruas do centro da capital enquanto a imagem mostra um cruzamento movimentado (14 maio 2016b). O Terra de Minas destaca a pressa como um efeito negativo da contemporaneidade, assim como a fragilidade das relações interpessoais, o que também é validado nas falas de pessoas comuns:

Maria das Graças (sonora, pessoa comum): hoje em dia, as pessoas estão muito olhando ele, ele, ele. Ivoltadas para si mesmas]. Esse trabalho filantrópico, essa reciprocidade, essa forma de agradar está muito difícil nos nossos tempos (TERRA DE MINAS, 7 mar. 2015).

Este tensionamento entre presente e passado oculta outro: o Interior x capital. Não apenas o modo de viver da simplicidade está em outro tempo, como também em outro espaço: no campo, longe do "progresso" e da "modernidade". Por este motivo, o Terra de Minas privilegia as cidades do interior como cenário para suas reportagens. É como se quisesse construir uma dimensão de que
Minas (autêntica, verdadeira) não se encontra na capital. No entanto, nos últimos anos, o programa tem se situado mais em Belo Horizonte.

Por ser absorvida pela modernidade, Belo Horizonte torna-se cenário de suas consequências positivas e negativas: ao mesmo tempo que representa o "progresso", representa a fuga dos valores ancestrais do estado. Diferentemente das demais localidades que visita, quando fala de $\mathrm{BH}$, o Terra de Minas costuma mostrar a ação negativa do tempo para então revelar algo positivo. Mantém-se o tom afirmativo do programa a respeito do estado e do "ser mineiro", buscando-se valorizar ações que resgatem a cidade dos problemas vividos. Segundo Musse,

[...] o cidadão típico da Modernidade Tardia, pelo menos aquele que vive nos grandes centros urbanos, tende a estar quase sempre em trânsito e conectado a algum suporte eletrônico, que lhe permita estabelecer contatos a longa distância, mas, certamente, o desassocia do ambiente do seu entorno. Tais aspectos, provenientes de uma rápida observação, estabelecem as bases de uma nova rede de sociabilidade, pautada menos no face a face $e$ mais nas relações mediadas por uma série de gadgets tecnológicos. [...] Da mesma forma, as relações afetivas com o patrimônio, com a paisagem urbana, parecem sofrer um desgaste natural (MUSSE, 2013, p. 229-230).

É contra esses efeitos da modernidade que o Terra de Minas se constrói. Enquanto o contemporâneo é marcado pela aceleração e correria, o passado tem um outro ritmo, mais lento, em que o afeto e as relações interpessoais podem ser vividos de forma autêntica e profunda. A modernidade trouxe facilidades para o dia a dia, mas "roubou" sabor e afeto. O programa legitima, por meio das vozes dos sujeitos entrevistados, um ritmo lento da vida cotidiana.

Para que ainda se encontre algum traço dos valores que configuram o ser mineiro projetado pelo programa, é preciso que ele o revele aos telespectadores. O jornalismo do Terra de Minas assume um papel de desvendamento e revelação (FRANCISCATO, 2005), de tirar do segredo os lugares que escondem um modo de vida que ainda 
dialoga com aquela tradição seletiva engendrada pelo programa e sua emissora. A legitimação social do Terra de Minas e sua longevidade perpassam o seu papel enquanto defensor do passado, enquanto espaço de preservação desse patrimônio. É recorrente o uso de expressões que indicam essa revelação: "Mas a nossa equipe encontrou moradores que conseguem manter essa amizade durante décadas" (TERRA DE MINAS, 14 maio 2016b); "No meio de tantos prédios, ruas e avenidas nem sempre a gente para observar as novidades que surgem por ai" (TERRA DE MINAS, 7 maio 2016a). Um estudo da socióloga Mônica Abdala sobre os hábitos de vida em cidades do interior de Minas Gerais e Goiás aponta que certas práticas comuns no passado já entraram em desuso. No entanto, afirma a autora que a

[...] experiência coletiva, permeada por formas de cooperação, solidariedade e vizinhança, em meios rurais e pequenas cidades que se tornaram centros rurais urbanizados [...] também podem ser apreendidos por meio da valorização e ressignificação das tradições em meio à vida urbana (ABDALA, 2011, p. 127).

Ou seja, marcas da vida comunitária do passado ainda encontram espaço para preservação de diversos agentes e, em certa medida, o Terra de Minas procura validar esse outro modo de viver como uma alternativa à correria e fugacidade. O programa almeja constituir o residual como dominante.

Por causa disso, Belo Horizonte do Terra de Minas quase que se restringe ao centro da cidade, espaço que mais sofreu os efeitos das políticas públicas em nome da modernização, e que, hoje, sofre com o desgaste da ausência de manutenção dos espaços públicos. Deste modo, o programa valoriza a cidade, pensada como "cidade do futuro", mas pouco problematiza as consequências desse futuro projetado, quase como se fossem provocadas naturalmente pelo tempo. Assim, uma outra forma de tratar o tempo no Terra de Minas é não apenas preservar os hábitos do passado, mas acenar para um futuro que aprimora as experiências ancestrais.

\section{O futuro como aprimoramento do passado}

Cabe, aqui, uma breve consideração sobre o que o Terra de Minas entende por "modernidade", que também se traduz por expressões como "progresso" ao longo do programa. Ao mesmo tempo que o programa esclarece a que tipo de tradição ele se refere - os hábitos de vida da sociedade rural, a simplicidade das pequenas casas, os afetos da comunidade - ele também dá ampla visibilidade aos edifícios com traços modernistas, aos artistas, aos avanços técnicos.

Por este motivo, na ocasião do aniversário de 120 anos da capital mineira, o programa colocou em seu primeiro bloco trechos de reportagens antigas em que se podia ver os espaços públicos do centro da cidade do modo como se vivia "nas primeiras décadas" do século XX. Com isso, o programa convoca o telespectador a uma posição de deslocamento, de estranhamento com os espaços que ele frequenta ainda hoje: a Praça da Liberdade, o Parque Municipal, onde se podia passear de barco, aspectos que convocam alguma nostalgia, mas que naturalizam as formas contemporâneas de viver.

Rocha (2017) explica que a América Latina entrou no que se considera modernidade de um modo próprio estabelecendo valores típicos regionais. Segundo a autora, entender a modernidade latino-americana é "entender que a televisão [...] cumpre papel decisivo na articulação entre o mundo simbólico do rural, do popular e a racionalidade técnico-instrumental do urbano" (ROCHA, 2017, p. 116). Por este motivo, falar em modernidade implica considerar suas contradições e mestiçagens. É nesse sentido que Silva (2017) afirma que Minas entrou na modernidade a partir de formas próprias.

No Terra de Minas, apesar da forte presença de um passado que o programa busca preservar, há o reconhecimento de que a cidade vivida no presente resulta da projeção de um futuro que prometia o bem comum. Se o tempo incidiu sobre a cidade trazendo consequências negativas, os avanços técnicos provenientes do "progresso" permitem um aprimoramento da experiência do passado no 
presente. Assim, se não é possivel viver no sítio para ter alimentos frescos, que se façam hortas urbanas. Este foi o tema de uma das reportagens exibidas no programa no dia 18 de novembro de 2017. $\mathrm{Na}$ cobertura de um edifício localizado no centro da capital, um grupo interdisciplinar de pesquisadores (biólogos, nutricionistas, engenheiros etc.) criaram uma horta que produz alimentos sem agrotóxico e conservantes. O repórter Vladmir Vilhaça ressalta o estranhamento da produção: "horta em terraço, assim, no centro da cidade, dá certo? As plantas sobrevivem assim?" (TERRA DE MINAS, 18 nov. 2017a).

A modernidade possibilita a reconfiguração de práticas do presente que se articulam ao passado, mas as transformam. A tecnologia funciona, então, como instrumento de resgate e aprimoramento do que havia de positivo no passado. O mesmo sentido se nota no tratamento do processo de restauração de obras de arte, monumentos e edificios da cidade, tema recorrente no programa, como a reportagem sobre a restauração dos cinemas de rua em Belo Horizonte. Após entrevistar moradores da região que guardam na memória experiências naquelas salas, a reportagem exibe o presidente da Fundação Municipal de Cultura, que explica o processo de restauração do prédio do Cine Santa Tereza, edifício inaugurado em 1948 que, após sofrer o desgaste do tempo, foi restaurado e reativado, mantendo os traços arquitetônicos de sua origem. Assim, o programa pretende instaurar um sentido de que a experiência do passado pode ser vivida hoje, mas com mais conforto.

Ao que parece, há uma vertente da modernidade que é aceita: o programa orgulha-se dos museus, da literatura, dos monumentos, mas eles ganham maior relevo quando associados a certa historicidade que, certamente, encontra respaldo nas políticas públicas de promoção de cultura. Embora lamente os danos da modernidade. o programa pouco problematiza a conjuntura desse mesmo passado que procura preservar: a chegada das monoculturas destinadas ao mercado global; a criação intensiva do gado; o desinteresse dos jovens em continuar os projetos dos pais, pequenos agricultores familiares, uma vez que seus projetos de futuro são fundados no sonho do progresso e do sucesso na vida urbana. (ABDALA, 2011, p. 137). Os efeitos perversos pouco aparecem problematizados no programa, que se por um lado quer oferecer resistência aos avanços do capitalismo, eles aparecem como um traço que o tempo traz por si só. O Terra de Minas sinaliza, no presente, para um futuro mais positivo e otimista que pode romper o caos do cotidiano. Esse futuro não oferece uma ruptura com o passado, uma vez que o utiliza como referência e como marco para uma continuidade.

\section{O passado como construção de si}

No entanto, de que passado o Terra de Minas está falando? A que momento histórico o programa se refere quando aciona um tempo que já não é mais em sua plenitude, mas que almeja seu retorno? Se o passado é um patrimônio que precisa ser preservado, isso decorre do fato de que, no programa, o passado se materializa nos sujeitos. Ao ativar constantemente a memória dos entrevistados, Terra de Minas deixa ver permanentemente um sentimento de nostalgia ou saudade. Assim, o programa endossa "o mito do passado mais feliz" (WILLIAMS, 2011a). Mais feliz porque quem efetua o exercício de rememorar o faz a partir do afeto, da juventude, da infância, de um tempo em que, supostamente, havia maior pureza e simplicidade. Sendo assim, o passado não possui um tempo definido, ele é o tempo de quem o viveu.

São poucos os momentos em que Terra de Minas dá precisão nas datas e periodos. O passado datado entra no programa enquanto dimensão legitimadora dos patrimônios - das igrejas, dos edificios etc. Mas a dimensão preferencial do passado no programa é da história de vida, o passado do sujeito. Deste modo, o programa não faz distinção entre a infância que se deu nos anos 1950 e a dos anos 1980, a conjuntura que conforma as práticas vividas em um e outro tempo pouco se expressa para dar significado temporal. Por esse motivo, o programa utiliza expressões genéricas como "antigamente" para falar do tempo histórico. 
A infância/juventude é um tempo frequentemente recorrido pelo programa, como na fala da artista plástica Maria Thereza que organiza diariamente um café nas ruas do centro de Belo Horizonte. Após mostrar a casa onde a artista viveu em sua infância ${ }^{6}$ e o relato do cotidiano de seu avô, ela conclui: "é como se eu estivesse relembrando esse passado que eu vivi. Esse cheiro de café constante na casa, com bolo. E eu estivesse reeditando essa história aqui na rua" (TERRA DE MINAS, 7 mar. 2015).

Terra de Minas procura evidenciar situações em que encontra espontaneamente pessoas passando pela rua no momento da gravação do programa para contar suas histórias. Para falar sobre os murais urbanos, o programa interpela duas entrevistadas por meio de expressões como "a senhora lembra"? (18 nov. 2017a). Na reportagem que abordou a renovação dos cinemas de rua em $\mathrm{BH}$, a sonora de leda Ferreira, que estava passando no momento de gravação, ratificou a mesma posição ao lembrar sua juventude:

leda Ferreira (advogada): tinha a roupa de vir ao cinema. Eu fiz uma vez um vestido lilás para vir ao Paté [...] e até hoje eu tenho um pouco da nostalgia do lilás. Era muito bom! Pena que você [repórter] não tenha vivido essa época (TERRA DE MINAS, 25 jun. 2016c).

Tanto quanto o parecer técnico de um especialista, o testemunho de quem viu e viveu possui forte peso na construção informativa e afetiva do programa. Como consequência, certos personagens são preferenciais na legitimação do discurso. Especialistas e fontes oficias têm lugares assegurados, mas também idosos, anciãos que tenham vivido aquele passado projetado no programa para assegurar uma experiência autêntica de outra temporalidade no presente. Com isso, Terra de Minas parece assumir também o papel de transmitir as experiências de geração em geração, fortalecendo um vínculo de pertencimento e criando um sentido de comunidade. Ainda sobre a reportagem sobre a restauração dos cinemas de rua, a produção teve como gancho a pesquisa realizada por duas jovens publicitárias em seu trabalho de conclusão de curso, cujo objetivo era mapear todas as salas de cinema de bairro em $\mathrm{BH}$, contar suas histórias e aviltar o testemunho de pessoas que tenham frequentado aqueles espaços. Sendo assim, ao lado da experiência de quem viveu o passado, há o desejo de saber das novas gerações.

O tempo da infância, o tempo vivido legitima-se no Terra de Minas e põe em contato a experiência de passado e presente na voz dos sujeitos. Em geral, a tentativa é de fazer uma crítica ao presente buscando restaurá-lo, é tomar o passado como horizonte para a construção de um modo de viver mais afetivo.

\section{Horizontes para uma agenda de investigação}

A partir do Estudos Culturais, Rocha (2017) afirma que a mestiçagem é uma condição da modernidade latino-americana. Isso se comprova na forma como a imagem da cidade de Belo Horizonte se constrói no Terra de Minas. BH é, ao mesmo tempo, a materialização da modernidadee do progresso do estado, e as tradições do interior. As duas dimensões coexistem no programa, que pouco problematiza suas contradições.

Ao fazer essa articulação, Terra de Minas constrói para si um lugar de distinção no telejornalismo local: enquanto os telejornais diários ratificam os efeitos negativos da modernidade - o trânsito intenso, a violência etc. - o Terra de Minas atua como fomentador de uma versão afetiva que a cidade carrega como continuidade do passado. Ao tratar Minas Gerais como um local onde o passado permanece, como se o tempo fosse linear, o programa, justamente, ratifica a temporalidade não linear e comprova que as distintas temporalidades vividas estão em articulação no mesmo momento histórico.

Há, também, um certo senso de arcaico no programa. A preservação, nesse caso, opera como uma tentativa de manter estática no tempo a experiência de um tempo que não se vive mais.

6 Hoje, aquela casa abriga uma ONG que cuida de menores em situação de risco por meio da arte. 
Diferentemente do passado como patrimônio, em que há uma tentativa de evidenciar os valores e práticas que permanecem ativos como resíduo, o arcaico diz de algo que ficou no passado e tornase peça de museu, como no caso dos enxovais do Museu da Renda (9 dez. 2017b).

A análise das temporalidades em programas televisivos mostra-se como um fértil campo de investigação para pesquisadores brasileiros. As temporalidades dizem da experiência do tempo nas sociedades contemporâneas que são atravessadas por políticas públicas de ocupação do espaço, tecnologias que transformam as formas de sociabilidade entre outros fatores que modificam a percepção sobre estar no tempo, o que também se traduz nos produtos midiáticos. Este artigo procurou levantar algumas dessas possibilidades, ainda de modo inicial, mas com a finalidade de apontar pistas para análises futuras.

\section{Referências}

ABDALA, Mônica Chaves. Saberes e sabores: tradições culturais populares do interior de Minas e de Goiás. História: Questões \& Debates, Curitiba, n. 54, p. 125-158, jan./jun. 2011. Editora UFPR. https://doi.org/10.5380/ his.v54i1.25743

COUTINHO, Iluska; MATA, Jhonatan. Telejornalismo a serviço do público: a voz do povo em cena. Revista Famecos, Porto Alegre, v. 17, n. 1, p. 65-73. jan./abr. 2010. https://doi.org/10.15448/1980-3729.2010.1.6881.

FRANCISCATO, Carlos Eduardo. A fabricação do presente: como o jornalismo reformulou a experiência do tempo nas sociedades ocidentais. São Cristóvão: Editora UFS; Aracaju: Fundação Oviêdo Teixeira, 2005. 274 p.

GOMES, Itania. Raymond Williams e a hipótese cultural da estrutura de sentimento. In: GOMES, Itania; JANOTTI, Jeder (org.). Comunicação e estudos culturais. Salvador: EDUFBA, 2011. p. 29-48.

LISBOA FILHO, Flavi Ferreira; ENNINGER, Rossana Zott. Identidade e televisão regional: conceitos e aproximações. Intercom - Sociedade Brasileira de Estudos Interdisciplinares da Comunicação, XXXVI Congresso Brasileiro de Ciências da Comunicação - Manaus/ AM - 4 a 7 set. 2013. Disponivel em http://w3.ufsm.br/ estudosculturais/arquivos/trabalhos-eventos/IDENTIDADE\%20E\%2OTELEVIS\%C3\%83O\%2OREGIONAL\%20 CONCEITOS\%20E\%2OAPROXIMA\%C3\%87\%C3\%95ES. pdf. Acesso em: 20 mar. 2018.

MARTÍN-BARBERO, Jesús. Dos meios às mediações comunicação, cultura e hegemonia. Rio de Janeiro: Editora UFRJ, 2006, p. 11-21.
MATA, Jhonatan. Um telejornal para chamar de seu: identidade, representação e inserção popular no telejornalismo local. Dissertação (Mestrado em Comunicação) - Faculdade de Comunicação, UFJF, Juiz de Fora, 2011.

MEAD, George Herbert. The nature of aesthetics experience. International Journal of Ethics, [s. l.], v. 36 n. 4, p. 382-393, 1926. https://doi.org/10.1086/intejethi.36.4.2377635.

MUSSE, Christina. Cultura, televisão e imaginário urbano. Matrizes, [s. l.], v. 7. n. 1, p. 223-234, jan./jun. 2013 https://doi.org/10.11606/issn.1982-8160.v7i1p223-234.

MUSSE, Christina; VARGAS, Herom; NICOLAU, Marcos. Apresentação - Temporalidades: dos conceitos às aplicações midiáticas. In: MUSSE, C.; VARGAS, H.; NICOLAU, M. (org.). Comunicação, mídias e temporalidades. Salvador: Edufba, 2017. p. 7-16.

RIBEIRO, Ana Paula; LEAL, Bruno; GOMES, Itania. A historicidade dos processos comunicacionais: elementos para uma abordagem. In: MUSSE, C.; VARGAS, H.: NICOLAU, M. (org.). Comunicação, mídias e temporalidades. Salvador: Edufba, 2017, p. 37-58.

ROCHA, Simone. "Ele é o atraso e você a modernidade": experiências anacrônicas da modernidade latino-americana na televisualidade brasileira, o caso da telenovela Duas Caras. In: FRANÇA, V.; COHEN, E.; GOMES, I. (org.). Gêneros midiáticos e identidade. Belo Horizonte: PPGCOM UFMG, 2017, p. 115-132.

SILVA, Fernanda Mauricio da; GUTMANN, Juliana. 0 feminino dá o tom: resultados de uma análise histórica e cultural do talk show no Brasil. Texto apresentado no XXVI Encontro Anual da Compós, São Paulo, jun. 2017.

SILVA, Marcos Vinícius. O estilo televisivo e a figuração da mineiridade em programas de caráter regional. 2017. Dissertação (Mestrado em Comunicação Social) - Faculdade de Filosofia e Ciências Humanas, UFMG, Belo Horizonte, 2017.

TERRA DE MINAS. Programa TV Globo Minas. 7 mar. 2015. TERRA DE MINAS. Programa TV Globo Minas. 7 maio 2016a. TERRA DE MINAS. Programa TV Globo Minas. 14 maio 2016b.

TERRA DE MINAS. Programa TV Globo Minas. 25jun. 2016c. TERRA DE MINAS. Programa TV Globo Minas. 18 nov. 2017 a. TERRA DE MINAS. Programa TV Globo Minas. 9 dez. $2017 \mathrm{~b}$. WILLIAMS, Raymond. O campo e a cidade: na história e na literatura. São Paulo: Companhia das Letras, 2011a.

WILLIAMS, Raymond. Cultura. Rio de Janeiro: Paz e Terra, 2011b.

WILLIAMS, Raymond. Marxismo e Literatura. Rio de Janeiro: Zahar Editores, 1979. p. 179-184. 


\section{Fernanda Mauricio da Silva}

Doutora e Pós-doutora em Comunicação e Cultura Contemporâneas pela Universidade Federal da Bahia (UFBA). Professora do Programa de Pós-Graduação em Comunicação e do Departamento de Comunicação Social da Universidade Federal de Minas Gerais (UFMG), Belo Horizonte, MG, Brasil.

\section{Endereço para correspondência}

Fernanda Mauricio da Silva

Universidade Federal de Minas Gerais

Av. Antônio Carlos, 6.627, Sala 4.238, $4^{\circ}$ Andar

Pampulha, 31.270-901

Belo Horizonte, MG, Brasil 